\title{
El Transporte Aéreo de Mercancías en los Aeropuertos Españoles: Hacia una Concentración e Internacionalización Selectivas
}

\section{The Air Freight Transport at Spanish Airports: Towards Selective Concentration and Internationalization}

\author{
Carlos López-Escolano \\ cle@unizar.es @ https://orcid.org/0000-0002-1653-7780 \\ Daniel Cruz-Alonso \\ 684072@unizar.es @ https://orcid.org/0000-0001-8264-1263 \\ Ángel Pueyo-Campos \\ apueyo@unizar.es 10 https://orcid.org/0000-0003-4103-2116 \\ Universidad de Zaragoza. Edficio Residencia de Profesores, $5^{\circ}$ Izquierda. Ciudad Universitaria \\ Campus San Francisco. C/Pedro Cerbuna 12. 50009 Zaragoza
}

\section{INFO ARTÍCULO}

Recibido: 22/12/2019

Revisado: 21/5/2019

Aceptado: 24/5/2019

PALABRAS CLAVE

Mercancías

Carga aérea

Aeropuertos

Globalización

España

\section{KEYWORDS}

Freight

Air cargo

Airports

Globalization

Spain

\section{RESUMEN}

El proceso de globalización requiere que los actores locales y regionales se incorporen en las redes y flujos económicos internacionales para lograr la competitividad y el desarrollo económico. Ello supone cambios que modifican los impactos y alcance de las infraestructuras de transporte. En el caso de la distribución de mercancías, el transporte aéreo supone un volumen reducido sobre el total de la carga internacional, donde solo unos cuantos aeropuertos centralizan la mayor parte del mismo. En España únicamente cuatro son relevantes en la gestión de carga aérea, en especial de la internacional. Esta investigación caracteriza los principales patrones de la carga aérea en los aeropuertos españoles mediante el análisis de su evolución reciente en torno a diferentes variables, evaluando algunos cambios notables que están modificando la jerarquía aérea. 


\section{INTRODUCCIÓN}

La aceleración de los procesos de globalización económica ha modificado de manera fundamental la organización de la economía global, intensificando la integración e interdependencia de la actividad económica transfronteriza (Coe, N. M., y Yeung, H. W. -C., 2015). Por ello, el transporte es un elemento fundamental para el desarrollo de la globalización a todas las escalas y en todos los ámbitos. Productores y consumidores de todo el mundo están ahora conectados mediante sistemas de transportes, logística y telecomunicaciones rápidos y eficaces que están reconfigurando las redes tradicionales de suministro y distribución (Dilian, C. D., y White, C. L., 2010). La globalización requiere así de complejos, robustos y eficaces sistemas de transporte necesarios para el intercambio global, rápido y masivo de personas y mercancías (Gago García, 2002); así como para facilitar el rápido crecimiento de algunas economías; asegurar los modelos productivos descentralizados, externalizados y deslocalizados; concentrar rentas; desarrollar la logística o fomentar el comercio electrónico (Rodrigue, J. P. et al., 2017; Sales, M., 2017).

Estas transformaciones conllevan importantes efectos en la escena internacional, pero también en espacios locales y, lógicamente, en las políticas de transporte. En este contexto, el transporte como factor de competitividad obliga a ciudades y territorios a buscar estrategias para incorporarse en las redes globales de distribución y suministro. Aunque factores tradicionales como la situación siguen siendo fundamentales (Savy, M., 2004) para la nueva red mundial de transporte de mercancías, la seguridad jurídica, la agilidad aduanera, la accesibilidad y la conectividad que otorgan los actuales medios de gestión y de transporte son determinantes importantes para mantener bajo control los costes del transporte internacional (Tovar B., et al., 2015). Ubicaciones centrales e intermedias se identifican como cualidades espaciales que mejoran los niveles de tráfico de los centros de transporte y, por lo tanto, indican qué lugares se ubican estratégicamente dentro de los sistemas de transporte globales o regionales (Fleming, D. K., y Hayuth, Y., 1994). Por lo tanto, interesa analizar y comprender la organización de los nodos y conexiones del sistema de transporte para desarrollar una adecuada planificación de las actividades económicas y de las infraestructuras.

Las grandes distancias que la globalización impone entre espacios productores y espacios consumidores suponen que los principales flujos internacionales de mercancías sean asumidos por el transporte marítimo gracias a su elevada capacidad y bajo coste. La jerarquía portuaria tradicional mundial se está modificando sin embargo aceleradamente por el rápido crecimiento de los puertos asiáticos (Akhavan, M., 2017), relegando a los puertos europeos y norteamericanos a posiciones intermedias, aunque fundamentales. Por su parte, el transporte terrestre es esencial y predomina la distribución en escalas regionales y de proximidad, en especial el modo carretero sobre el ferroviario. Además, en los próximos años cabrá prestar especial atención al impacto del reparto de "última milla" en los entornos urbanos (Lim, S. F. W. T., et al., 2018). Mientras, el transporte aéreo de carga supone una parte poco significativa sobre el total de los desplazamientos de mercancías a pesar de su papel estratégico en el comercio internacional (Yamaguchi, K., 2008), por ser determinante en sectores con alto valor añadido (Morrell, P. S., 2011; Sales, M., 2017) y/o que requieren una distribución inmediata (Lotti, R., y Caetano, M., 2018). Impulsado por el auge del comercio electrónico (Boeing, 2017), se prevén durante los próximos veinte años crecimientos anuales medios del volumen de mercancías transportadas por avión de un 4,2\% y un aumento del número de aviones de carga del $70 \%$.

De este modo, el transporte aéreo puede entenderse como una práctica que permite valorar los procesos de interconectividad que acontecen en el orden global (Córdoba Ordóñez, J. A., y Gago García, C., 2012; Gago García, C., y Córdoba Ordóñez, J. A., 2013). A pesar de su interés estratégico, las investigaciones realizadas sobre este último modo a nivel internacional se centran mayoritariamente en el análisis de la estructura y flujos de las redes de transporte aéreo de mercancías (Hui, G. W. L., et al., 2004; Matsumoto, H., 2004; Fung, M. K. Y., et al., 2005; Derudder, B. et al., 2008; Dang, Y. R., y Peng, L. N., 2012; Mayer, R., 2016; Sales, M., 2017; Gong, Q. et al., 2018; Suwanwong, T. et al., 2018); así como en el estudio de casos para las terminales aeroportuarias (Zhang, A., 2003; Hwang, C. C., y Shiao, G. C., 2011; Hesse, M., 2014; Walcott, S. M., y Fan, Z., 2017), 
en especial para determinados productos y mercancías (Lotti, R., y Caetano, M., 2018) o empresas (Bowen Jr., J. T., 2012; Balliauw, M. et al., 2018).

En el caso español, la literatura existente sobre esta temática es ciertamente reducida (López, C., et al., 2015), contrastando con la mayor variedad de las investigaciones que abordan los desplazamientos aéreos de pasajeros y los que analizan las terminales aeroportuarias (Antón, F. J. et al., 1994; Rey, M. B., 2003; Martí-Henneberg, J. et al., 2007; Tapiador, F. J. et al., 2008; Escalona, A. I., y Ramos, D., 2010; Suau-Sánchez, P., y Burghouwt, G., 2011; Jiménez, J. L., y Betancor, O., 2012; Ramos, D. et al., 2013; Martín, J. C. et al., 2014; Díez, R. et al., 2016).

Por su interés para el desarrollo económico es importante que planificadores y otros actores involucrados comprendan los cambios en las redes aéreas globales ante el papel que estas pueden desempeñar para una ciudad o región en cuanto a su integración y gestión de la capacidad aérea (Wong, W. H. et al., 2019), así como por su posicionamiento y jerarquía (Derudder, B. et al., 2008; Matsumoto, H., 2004), o el impulso a las actividades logísticas y económicas de sus entornos. De este modo, determinados lugares están configurando una red que concentra actividades y que cada vez se encuentra más desconectada de sus entornos inmediatos (Gago García, C., y Córdoba Ordóñez, J. A., 2013) por la nueva concepción flexidimensional de los espacios geográficos (Pueyo, Á. et al., 2018) que refuerza los lazos de los territorios en distintas escalas y temporalidades.

En este contexto, este trabajo avanza en la interpretación de los flujos de transporte aéreo de mercancías con el objetivo de valorar la inserción de los aeropuertos españoles en las redes globales de distribución. Para ello, se caracteriza la evolución reciente y las especificidades de las conexiones de las redes de carga aérea reflexionando, a su vez, sobre su interés estratégico por las implicaciones socioeconómicas y territoriales en la planificación de infraestructuras. Aun considerando el enfoque de tipo descriptivo de este trabajo, se valora sin embargo el interés de una aportación que contextualice este ámbito en España por la importancia para la competitividad económica actual y futura de muchos de sus territorios.

Revisado el contexto e interés de la investigación, el resto del trabajo se organiza del siguiente modo: el apartado segundo expone las características y la jerarquía global actual del sistema de carga aérea; la sección tercera describe las características de la zona de estudio, los datos y métodos empleados; la sección cuarta muestra los resultados obtenidos; la sección quinta sirve como discusión del trabajo; y por último la sección sexta recoge las principales conclusiones.

\section{JERARQUÍA GLOBAL DE LA CARGA AÉREA}

Como se ha comentado en el apartado anterior, el transporte aéreo de mercancías supone un modo minoritario sobre el volumen total de la carga transportada en el mundo, si bien su valor económico hace que sea un modo estratégico. El volumen de mercancías transportadas por avión muestra un incremento constante durante los últimos años (figura 1) aunque ralentizado desde 2011 por el exiguo crecimiento del comercio mundial, pero con previsiones que apuntan a un crecimiento medio anual del 4,2\% (Boeing, 2017). En 2016 se transportaron por vía aérea un total de 54.932 .000 t, un 4,4\% más que el año anterior (IATA, 2017). Este crecimiento va a conllevar importantes efectos sobre la industria aeronáutica, como el aumento previsto del número de aviones de carga en torno al $70 \%$ durante los próximos veinte años, ayudado por el empuje del comercio electrónico (Boeing, 2017), pero también en las terminales aeroportuarias y en las zonas de actividades logísticas asociadas (Verhetsel, A. et al., 2015).

La distribución aérea de mercancías se concentra en una selección de flujos principales donde un número reducido de aeropuertos actúa como nodos centrales del sistema (Guimerà, R., y Amaral, L. A. N., 2004). En este sentido, el $86,3 \%$ de las mercancías globales transportadas por vía aérea en 2016 pasó por los veinte principales aeropuertos (tabla 1), mostrando la elevada concentración del sector.

Estos aeropuertos (tabla 1) actúan como hubs conectores y redistribuidores de mercancías al igual que sucede con los tráficos de pasajeros (O’Kelly, 1998; Bryan, D. L., y O’Kelly, M. E., 1999). Su localización, bien sea 


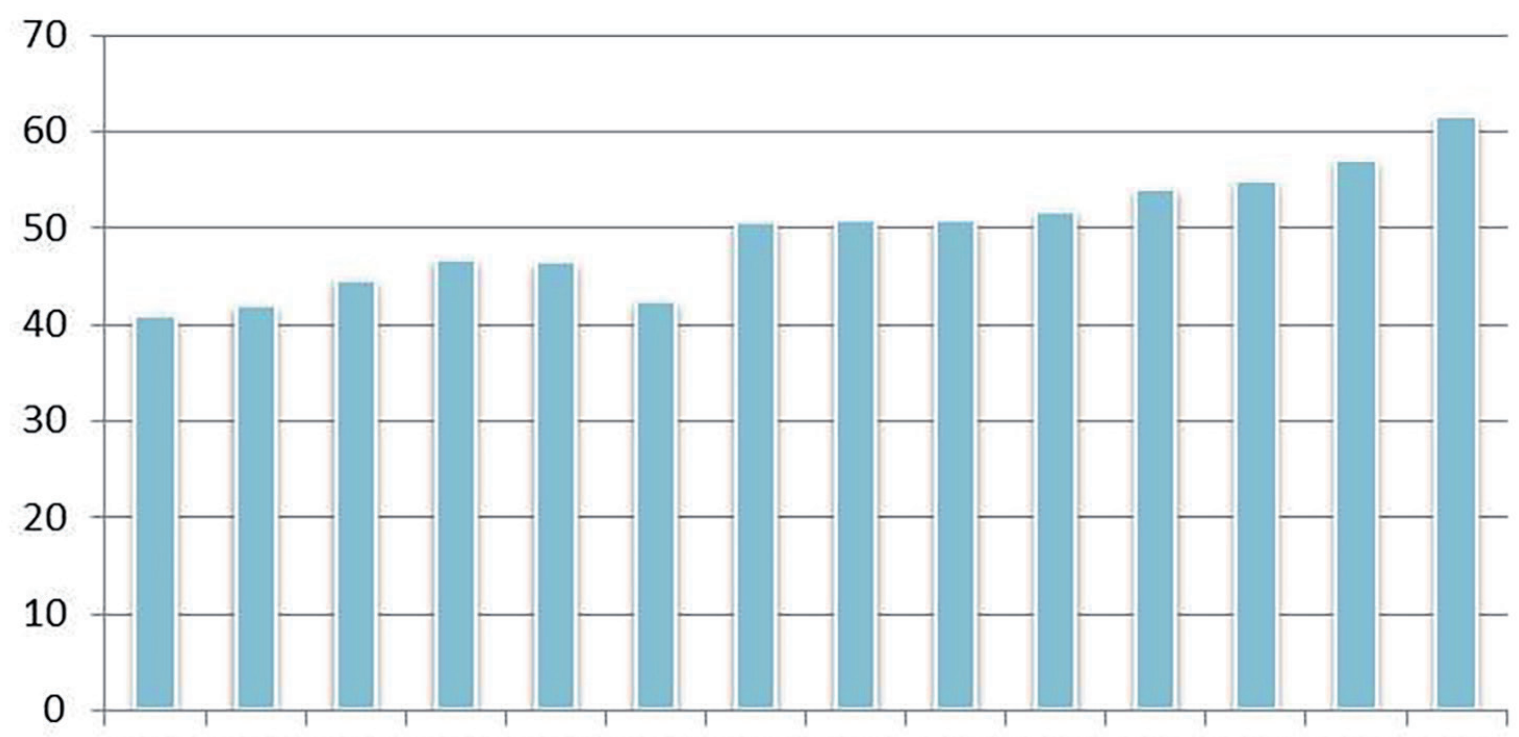

20042005200620072008200920102011201220132014201520162017

Volumen (millones t métricas)

Figura 1. Evolución de la carga aérea global, 2004-2017.

Fuente: Statista, 2018. Elaboración propia, 2018.

central o intermedia en el sistema global (Fleming, D. K., y Hayuth, Y., 1994), coincide con espacios estratégicos ubicados dentro de la cadena global de producción, suministro, logística e intermodalidad (Savy, M., 2004). La mayor parte de estos aeropuertos son a su vez hubs globales para el tráfico de pasajeros, como Hong Kong, Shanghai, Dubai, Tokyo-Narita o París-Charles de Gaulle, entre otros; aunque sin embargo las necesidades especiales que requiere el transporte de carga aérea (Mayer, R., 2016) supone que algunos aeropuertos que no presentan especial interés para el tráfico de pasajeros y no se encuentren en áreas geográficas centrales se están configurando como nodos óptimos para el transporte de mercancías (Behrens, K., 2007) en un papel de terminales intermediarias. Así, destacan los aeropuertos de Memphis, Anchorage o Louisville.

Por su parte, los aeropuertos de la Unión Europea (UE-28) gestionaron un total de 15.179.000 de toneladas de mercancías en 2016 (Eurostat, 2018), de las cuales un 94,1\% pasaron por alguno de los veinte principales aeropuertos europeos (tabla 2). Estas terminales presentan un papel global para la cadena de distribución de mercancías atendiendo al tipo de conexión de sus flujos y al volumen gestionado. La mayor parte de estos aeropuertos son también importantes hubs para el tráfico de pasajeros, como París-Charles de Gaulle, Frankfurt, Ámsterdam-Schipol, Londres-Heathrow, Bruselas, Madrid-Barajas o Munich, entre otros. Otra categoría de aeropuertos la conforman aquellos especializados en mercancías y que, en cambio, no son tan relevantes respecto al tráfico de pasajeros, como Leipzig-Halle, Luxemburgo o Colonia-Bonn. Una tercera categoría sería la de aquellos aeropuertos que están altamente especializados en el tráfico de mercancías, como Lieja o East Midlands.

La gestión del transporte de carga aérea se concentra también en unas cuantas empresas o aerolíneas, como se muestra en la tabla 3. En general, las bases centrales de estas operadoras coinciden con los principales aeropuertos de carga aérea, exceptuando United Parcel Service (UPS) que tiene su sede en Atlanta, ciudad cuyo aeropuerto no figura entre los principales para el manejo de mercancías pero que sin embargo ocupa el primer puesto global en número de pasajeros. 
Tabla 1. Principales aeropuertos de carga aérea en el mundo en 2016.

\begin{tabular}{|c|c|c|c|}
\hline Puesto & Aeropuerto (Código) & Estado & Volumen (t) \\
\hline 1 & Hong Kong (HKG) & China (Hong Kong) & 4.615 .241 \\
\hline 2 & Memphis (MEM) & Estados Unidos & 4.322 .071 \\
\hline 3 & Shanghai (PVG) & China & 3.440 .280 \\
\hline 4 & Incheon (ICN) & Corea del Sur & 2.714 .341 \\
\hline 5 & Dubai (DXB) & Emiratos Árabes Unidos & 2.592 .454 \\
\hline 6 & Anchorage (ANC) & Estados Unidos & 2.542 .526 \\
\hline 7 & Louisville (SDF) & Estados Unidos & 2.437 .010 \\
\hline 8 & Tokyo-Narita (NRT) & Japón & 2.165 .427 \\
\hline 9 & Paris-Charles de Gaulle (CDG) & Francia & 2.135 .172 \\
\hline 10 & Frankfurt-Main (FRA) & Alemania & 2.113 .594 \\
\hline 11 & Taipei (TPE) & Taiwán & 2.097 .228 \\
\hline 12 & Miami (MIA) & Estados Unidos & 2.014 .205 \\
\hline 13 & Singapore (SIN) & Singapur & 2.006 .300 \\
\hline 14 & Los Angeles (LAX) & Estados Unidos & 1.993 .308 \\
\hline 15 & Beijing (PEK) & China & 1.943 .159 \\
\hline 16 & Doha (DOH) & Qatar & 1.758 .074 \\
\hline 17 & Amsterdam-Schipol (AMS) & Países Bajos & 1.694 .729 \\
\hline 18 & Guangzhou (CAN) & China & 1.652 .215 \\
\hline 19 & London-Heathrow (LHR) & Reino Unido & 1.640 .400 \\
\hline 20 & Chicago-O'Hare (ORD) & Estados Unidos & 1.528 .136 \\
\hline
\end{tabular}

Fuente: Airports Council International, 2018. Elaboración propia, 2018.

Tabla 2. Principales aeropuertos de carga aérea en la Unión Europea en 2016.

\begin{tabular}{|c|l|l|c|}
\hline Puesto & \multicolumn{1}{|c|}{ Aeropuerto (CODIGO) } & Estado & Volumen (t) \\
\hline 1 & Paris-Charles de Gaulle (CDG) & Francia & 2.211 .265 \\
\hline 2 & Frankfurt-Main (FRA) & Alemania & 2.111 .358 \\
\hline 3 & Ámsterdam-Schipol (AMS) & Países Bajos & 1.771 .106 \\
\hline 4 & London-Heathrow (LHR) & Reino Unido & 1.637 .582 \\
\hline 5 & Leipzig-Halle & Alemania & 1.044 .952 \\
\hline 6 & Luxembourg & Luxemburgo & 801.058 \\
\hline 7 & Köln-Bonn & Alemania & 768.138 \\
\hline 8 & Liège & Bélgica & 592.146 \\
\hline
\end{tabular}




\begin{tabular}{|c|l|l|c|}
\hline Puesto & \multicolumn{1}{|c|}{ Aeropuerto (CODIGO) } & Estado & Volumen (t) \\
\hline 9 & Milano-Malpensa & Italia & 548.765 \\
\hline 10 & Brussels & Bélgica & 472.710 \\
\hline 11 & Madrid-Barajas & España & 404.284 \\
\hline 12 & München & Alemania & 353.495 \\
\hline 13 & East Midlands & Reino Unido & 319.609 \\
\hline 14 & London-Stansted & Reino Unido & 245.658 \\
\hline 15 & Wien-Schwechat & Austria & 216.382 \\
\hline 16 & Kobnehavn-Kastrup & Dinamarca & 185.691 \\
\hline 17 & Helsinki-Vantaa & Finlandia & 182.198 \\
\hline 18 & Roma-Fiumicino & Italia & 160.904 \\
\hline 19 & Dublin & Irlanda & 134.207 \\
\hline 20 & Bergamo-Orio al Serio & Italia & 117.660 \\
\hline
\end{tabular}

Fuente: Eurostat. Elaboración propia, 2018.

Tabla 3. Liderazgo de líneas aéreas en la carga aérea global en 2017. Movimientos nacionales e internacionales.

\begin{tabular}{|c|c|c|c|c|}
\hline Puesto empresa & Empresa & $\begin{array}{c}\text { Volumen } \\
\text { (millones t por km) }\end{array}$ & Sede (Estado) & Puesto aeropuerto \\
\hline 1 & FedEx & 16.851 & $\begin{array}{l}\text { Memphis } \\
\text { (Estados Unidos) }\end{array}$ & $2^{\circ}$ (global) \\
\hline 2 & Emirates & 12.715 & $\begin{array}{l}\text { Dubai } \\
\text { (Emiratos Árabes } \\
\text { Unidos) }\end{array}$ & $5^{\circ}$ (global) \\
\hline 3 & UPS & 11.940 & $\begin{array}{l}\text { Atlanta (Estados } \\
\text { Unidos) }\end{array}$ & $\begin{array}{l}1^{\circ} \text { pasajeros } \\
\text { (global) }\end{array}$ \\
\hline 4 & Qatar Airways & 10.999 & Doha (Qatar) & $16^{\circ}$ (global) \\
\hline 5 & Cathay Pacific Airways & 10.772 & $\begin{array}{l}\text { Hong Kong } \\
\text { (China, Hong Kong) }\end{array}$ & $1^{\circ}$ (global) \\
\hline 6 & Korean Air & 8.015 & $\begin{array}{l}\text { Seúl -Incheon- } \\
\text { (Corea del Sur) }\end{array}$ & $4^{\circ}$ (global) \\
\hline 7 & Cargolux & 7.322 & Luxemburgo & $6^{\circ}(\mathrm{EU}-28)$ \\
\hline 8 & Lufthansa & 7.317 & $\begin{array}{l}\text { Colonia/Frankfurt } \\
\text { (Alemania) }\end{array}$ & $\begin{array}{l}7^{\circ} \text { (UE-28)/ } \\
10^{\circ} \text { (global) } \\
\text { y } 2^{\circ}(\text { EU-28) }\end{array}$ \\
\hline 9 & Air Chine & 6.701 & Beijing (China) & $15^{\circ}$ (global) \\
\hline 10 & Singapore Airlines & 6.592 & Singapore (Singapur) & $13^{\circ}$ (global) \\
\hline
\end{tabular}

Fuente: Statista, 2018. Elaboración propia, 2018. 


\section{DATOS Y MÉTODOS}

Extrapolando este análisis a las características básicas del sistema aeroportuario español, en primer lugar, cabe destacar que el sistema aeroportuario español está configurado por una red de 52 aeropuertos de muy diferxentes características (figura 2). La mayor parte de se engloba en la empresa pública Aeropuertos Españoles y Navegación Aérea (Aena)' ${ }^{1}$ que gestiona 46 terminales y dos helipuertos, y que suponen la mayor parte del tráfico de pasajeros y mercancías. Aunque todas las Comunidades Autónomas disponen al menos de alguna terminal aérea, no todos los aeropuertos mantienen vuelos regulares o estacionales para viajeros y/o carga aérea (Pueyo, Á., et al., 2017). Por su parte, doce provincias no disponen de instalaciones aeroportuarias.

La red de Aena se complementa con otros aeropuertos gestionados por otras administraciones o sociedades, que no han sido considerados en este estudio. Se trata de los aeropuertos de Lleida-Alguaire y Andorra-la Seu d'Urgell (gestionados por Aeroports de Catalunya), Castellón (Aerocas), y Teruel (Consorcio del Aeropuerto de Teruel). Por su parte, el aeropuerto de Ciudad Real (Ciudad Real International Airport) no presta actualmente ningún servicio aéreo, si bien se espera que lo haga próximamente orientado al mantenimiento de aeronaves y a la carga aérea.

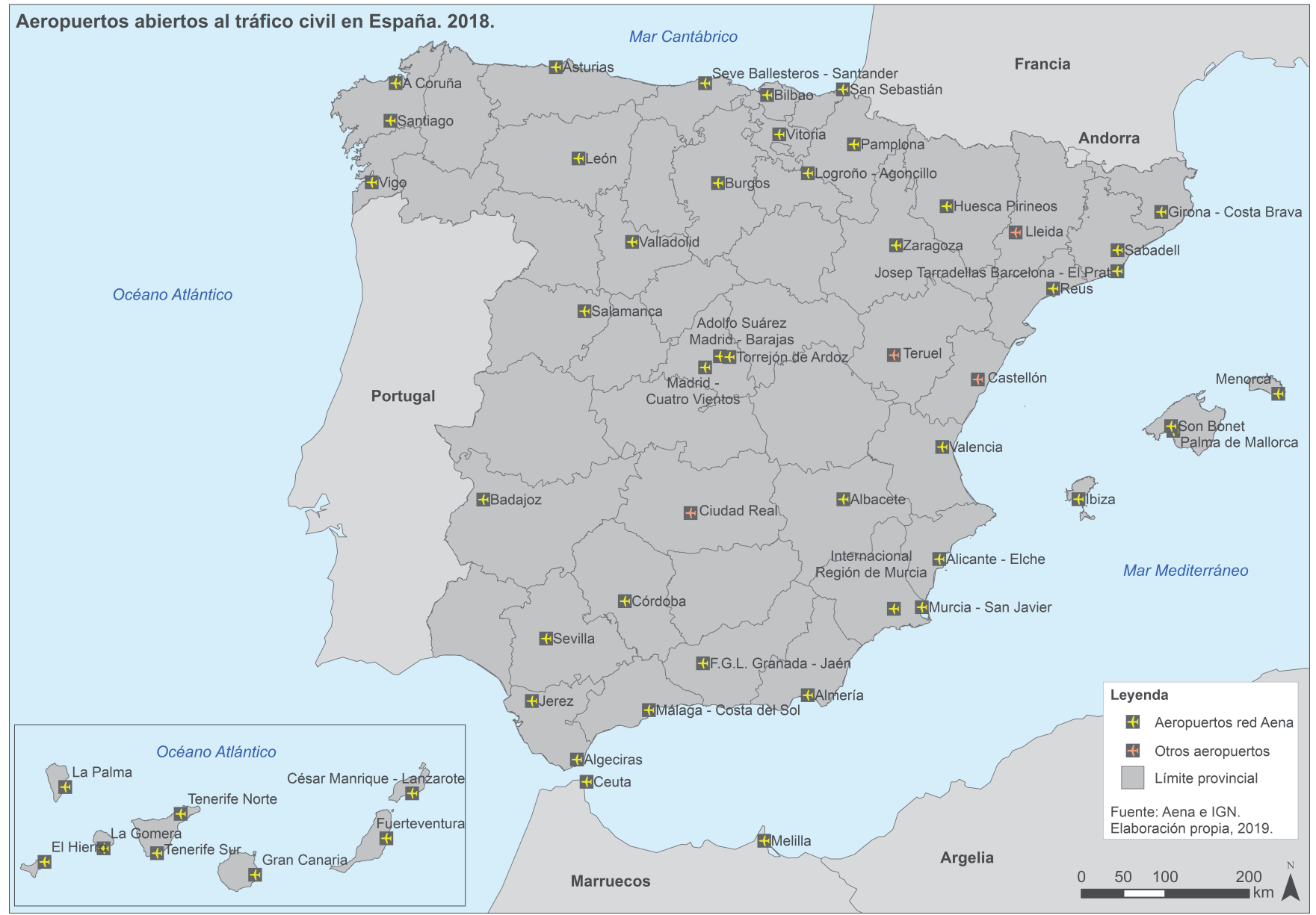

Figura 2. Mapa de aeropuertos abiertos al tráfico civil en España. Fuente: Instituto Geográfico Nacional, 2016. 
Para analizar la situación y evolución de la carga aérea en el sistema de aeropuertos españoles se ha obtenido información del servicio estadístico de Aena $^{2}$. Se han considerado como variables el volumen total de carga gestionada (2000-2017) y el número de conexiones internacionales (a nivel de país) existentes (20042017). Con esta información se ha creado una base de datos que facilita el análisis de:

1. La evolución del volumen de carga aérea total gestionada por la red Aena para el periodo 2000-2017.

2. La variación en el número de conexiones internacionales atendiendo al número de países con origen/ destino de carga aérea en cada aeropuerto de la red Aena para el periodo 2004-2017.

3. La evolución de la carga según el origen/destino por volumen: nacional, Unión Europea, resto de Europa, internacional (excluyendo a los países de la Unión Europea y del resto de Europa).

\section{RESULTADOS}

\subsection{Evolución del volumen de carga aérea}

Para ilustrar la evolución del sector de la carga aérea en España en los últimos años cabe mencionar que el incremento en el volumen gestionado por el conjunto de aeropuertos de la red Aena entre los años 2000 y 2017 ha sido de un 48,6\%, pasando de 617.808 t en el año 2000 a 918.305 t en 2017 (figura 3). A pesar de esta tendencia positiva, se observa como entre los años 2000 y 2008 la situación se mostró estable, apreciándose en 2009 el mayor descenso de la serie consecuencia de la Gran Recesión. Desde este año, el volumen de carga se recupera, con especial intensidad a partir de 2014. Por su parte, el peso de las mercancías transportadas entre aeropuertos españoles y otros países aumenta de forma considerable impulsado por la internacionalización de la economía española, mientras que desciende el total del volumen intercambiado entre aeropuertos españoles.

En este contexto, debe mencionarse que el número de aeropuertos que operan mercancías se ha reducido de 39 en el año 2000 a 34 en 2017, aunque en el mismo periodo el número de aeropuertos operados por Aena aumentó de 42 a 48 (incluidos los helipuertos de Ceuta y Algeciras). En la figura 4 se aprecia la evolución de los cuatro principales aeropuertos de carga aérea (base 2017) que en el transcurso del periodo de estudio han pasado de gestionar el 71,1\% en el año 2000 al 90,3\% en 2017. Esta jerarquía la componen los aeropuertos de Madrid, Barcelona, Zaragoza y Vitoria en 2017, aunque en los años iniciales Gran Canaria ocupaba el lugar de Zaragoza.

El aeropuerto que mayor peso tiene en el conjunto del sistema es Adolfo Suárez-Madrid Barajas, con el $51,3 \%$ del total del volumen de carga en 2017, cifra que mantiene sin grandes cambios desde el año 2000 (50,3\%). A cierta distancia se sitúa Barcelona-El Prat, aeropuerto que ha aumento su peso en el sistema al pasar del 14,4\% en el año 2000 al 17\% del volumen total en 2017. Ambos aeropuertos se benefician de ser los principales hubs nacionales e internacionales para el tráfico de pasajeros, lo que supone poder aprovechar determinados vuelos, como los de largo radio, para la carga simultánea de mercancías. Además, ambas ciudades son plataformas naturales para la actividad logística y de distribución de mercancías para el resto del Estado, además de atender amplios hinterlands, zonas industriales y espacios densamente poblados. El aeropuerto de El Prat se encuentra junto al puerto de Barcelona y la Zona Franca; mientras que Barajas se ubica en el corredor del Henares, espacio industrial y especializado en empresas de servicios logísticos y de transporte.

A continuación, se ubican dos aeropuertos del valle del Ebro, Zaragoza con el 15,5\% del volumen total, y Vitoria-Gasteiz con el 6,6\%. En el caso de Zaragoza la evolución ha sido muy significativa, pues en el año 2000 apenas pasaba por su terminal el $0,6 \%$ de la carga total. Por su parte, Vitoria-Gasteiz ha mejorado modestamente sus datos en este periodo. Se trata de dos aeropuertos con escasa relevancia en el tráfico de pasajeros, pero especializados en la operación de vuelos de carga gracias a su situación estratégica y a la excelente accesibilidad terrestre. En las inmediaciones de ambos aeropuertos han surgido en los últimos años espacios e instalaciones dedicadas a la actividad logística, como PlaZa en Zaragoza o Arasur en Vitoria-Gasteiz, que aprovechan las excelentes instalaciones de intercambio modal tren-avión-carretera en áreas

2. Aena estadísticas: <http://www.aena.es/csee/Satellite?pagename=Estadisticas/Home>. 


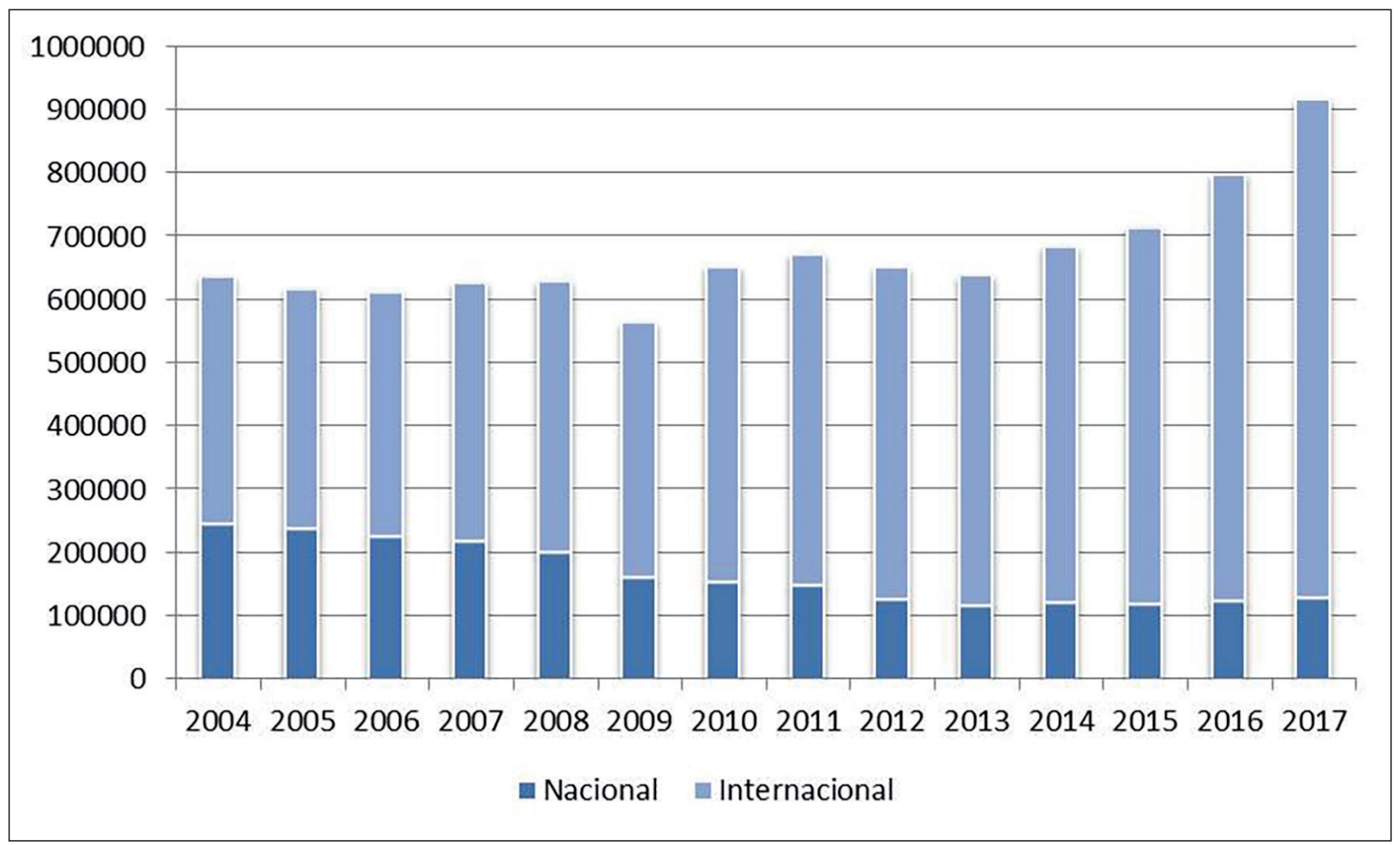

Figura 3. Evolución de las mercancías aéreas en España según tráfico nacional e internacional, 2000-2017. Fuente: Aena, 2018. Elaboración propia, 2018.

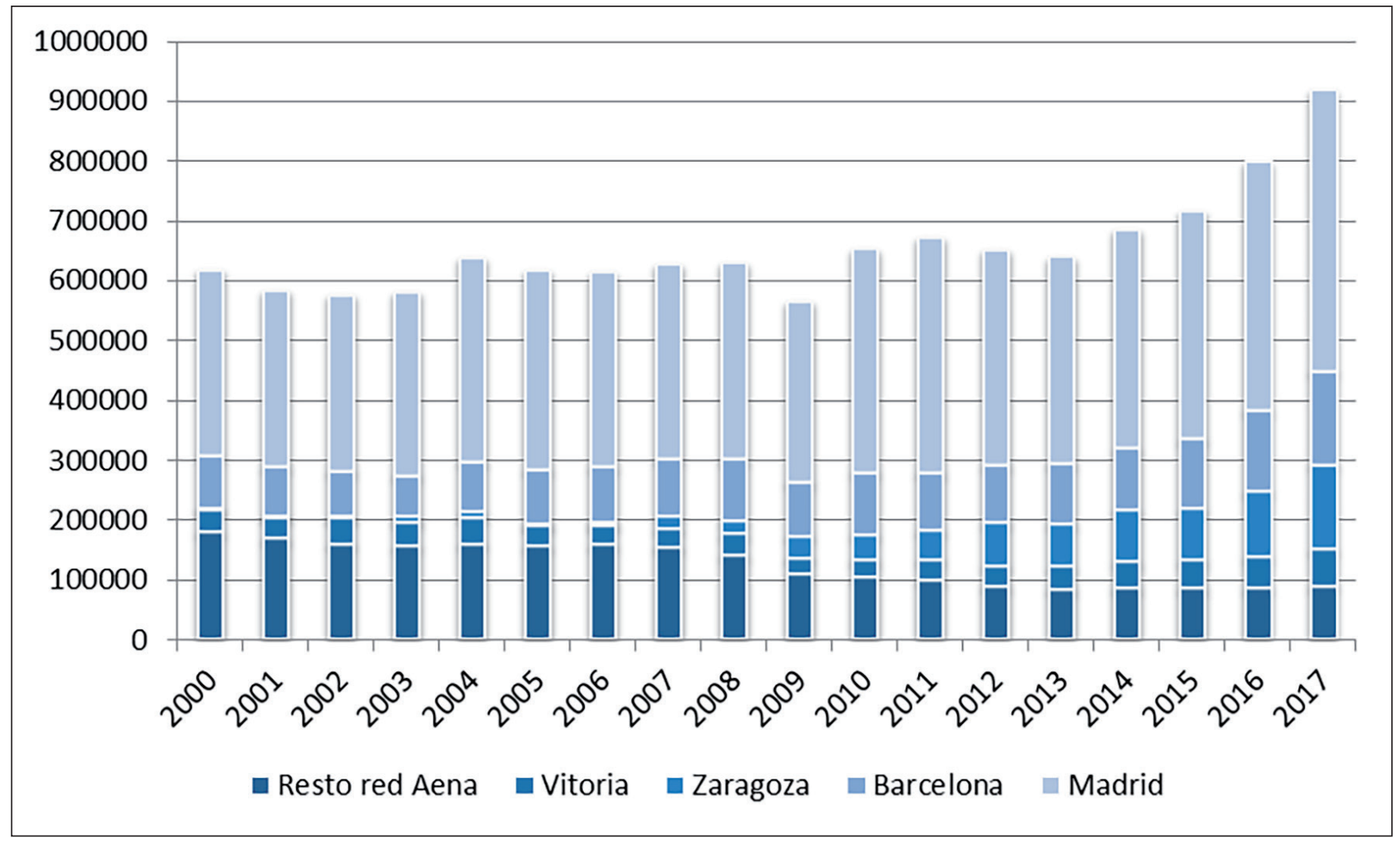

Figura 4. Evolución de las mercancías aéreas en España por aeropuertos, 2000-2017. Fuente: Aena, 2018. Elaboración propia, 2018. 
poco congestionadas. Además, Zaragoza aprovecha su renta de situación en el cuadrante nororiental de la península Ibérica, mientras Vitoria-Gasteiz lo hace en el norte peninsular.

Como se observa en la tabla 4, los veinte principales aeropuertos para la carga aérea de mercancías (que suponen el 99,5\% del total el volumen en 2004 y el 99,9\% en 2017) se mantienen sin la irrupción de otros que escalen posiciones durante el periodo analizado. Sin embargo, sí se aprecian variaciones internas, en especial en la parte media-alta de la clasificación. Madrid $\left(1^{\circ}\right)$ y Barcelona $\left(2^{\circ}\right)$ no han variado sus posiciones en la jerarquía, mientras que Vitoria-Gasteiz ha perdido una ( $3^{\circ}$ en 2004 y $4^{\circ}$ en 2017). En 2004 eran los principales aeropuertos insulares los que ocupaban las siguientes posiciones (Gran Canaria, Tenerife-Norte, Palma de Mallorca, Lanzarote, Ibiza, Menorca, Fuerteventura, La Palma) y otros en ciudades principales (Valencia, Zaragoza, Málaga, Alicante-Elche, Sevilla, Santiago, Bilbao, Vigo). Su evolución hasta 2017 muestra que todos ellos pierden un volumen significativo respecto a 2004, exceptuando Zaragoza, Valencia y Sevilla. Se territorializa de este modo el cambio del modelo de transporte aéreo en España motivado por el aumento de las exportaciones en los últimos años ${ }^{3}$ que beneficia especialmente a espacios como Zaragoza o Vitoria-Gasteiz.

De este modo, Adolfo Suárez-Madrid Barajas y Barcelona-El Prat mantienen su jerarquía y peso, mostrando cierta falta de capacidad para crecer en el segmento del transporte de mercancías, lo cual conlleva a una desconcentración de las operaciones mediante una diversificación hacia instalaciones intermedias (especialmente Zaragoza y en menor grado Vitoria-Gasteiz), provocada por los efectos de falta de espacio logístico en las inmediaciones de Barajas y El Prat así como por la mayor saturación de sus instalaciones por vuelos de pasajeros. Además de estos cuatro aeropuertos principales, destaca el comportamiento del aeropuerto de Sevilla que, aunque operó tan solo el 1,2\% del total en 2017, ha duplicado el volumen de carga, mejorando cinco puestos en la jerarquía y erigiéndose como el principal aeropuerto de carga del sur peninsular por delante de Málaga-Costa del Sol (principal aeropuerto andaluz para el tráfico de pasajeros).

En la situación opuesta (pérdida de volumen gestionado, de representatividad y de jerarquía) destacan los aeropuertos insulares, tanto del archipiélago canario como del balear. En conjunto, los aeropuertos de Canarias (Gran Canaria, Tenerife-Norte, Tenerife-Sur, Lanzarote, Fuerteventura y La Palma -los de El Hierro y La Gomera no entran en los veinte primeros puestos-) han pasado de operar conjuntamente el 13,7\% de las mercancías al 4,1\% en 2017. Por su parte, los aeropuertos de Baleares (Palma de Mallorca, Menorca e Ibiza -se excluye Son Bonet-) operaban en 2004 el 4,5\% del total, mientras que han gestionado un 1,5\% en 2017. Aunque el auge de algunos aeropuertos peninsulares, por su vocación exportadora, esté provocando la pérdida de representatividad de los aeropuertos insulares, cabe profundizar en el futuro sobre las causas del importante descenso en el volumen gestionado por estas terminales ante las necesidades específicas de suministro propias a su condición de insularidad.

\subsection{Variación del número de conexiones internacionales}

La organización de la carga aérea presenta una diversidad de orígenes y destinos que ha evolucionado de distinta manera e intensidad (figura 5 y tabla 6). Entre 2004 y 2017 no hubo variaciones significativas ya que el número de países con intercambio de mercancías ha aumentado de 93 a 103, y el número de aeropuertos ha disminuido de 382 a 374 en el conjunto de la red Aena. Se observa así una tendencia positiva a la internacionalización de los destinos con un leve aumento que, no obstante, es variable entre cada año, pero sin que ello implique la existencia de una red más amplia de aeropuertos conectados. Ello constataría por lo tanto un proceso de optimización y especialización de las terminales aeroportuarias de carga, respondiendo a los cambios en los modelos de organización y gestión de las aerolíneas y empresas logísticas siguiendo los patrones de la red global, así como de la mayor apertura de la economía española tras la Gran Recesión mediante la búsqueda de mercados fuera de su espacio habitual.

Existen sin embargo matices entre los cuatro aeropuertos principales. Por países, todos excepto Vitoria-Gasteiz han incrementado el número de orígenes/destinos, destacando especialmente el aumento de

3. ICEX: <https://www.icex.es/icex/es/Navegacion-zona-contacto/revista-el-exportador/en-cifras/index.html\#seccion3> 
Tabla 4. Principales aeropuertos de carga aérea en España en 2004 y 2017 según volumen gestionado. Base 2017.

\begin{tabular}{|c|c|c|c|c|c|}
\hline \multirow{2}{*}{ Aeropuerto } & \multicolumn{2}{|c|}{2004} & \multicolumn{2}{|c|}{2017} & \multirow{2}{*}{$\begin{array}{l}\text { Diferencia volumen (\%) } \\
\text { 2004-2017 }\end{array}$} \\
\hline & Volumen (t) & Puesto & Volumen (t) & Puesto & \\
\hline Adolfo Suárez-Madrid Barajas & 341.177 & 1 & 470.796 & 1 & $38,0 \%$ \\
\hline Barcelona-El Prat & 84.985 & 2 & 156.105 & 2 & $83,7 \%$ \\
\hline Vitoria-Gasteiz & 43.683 & 3 & 60.484 & 4 & $38,7 \%$ \\
\hline Gran Canaria & 40.935 & 4 & 18.045 & 5 & $-55,9 \%$ \\
\hline Tenerife-Norte & 23.647 & 5 & 13.044 & 7 & $-44,8 \%$ \\
\hline Palma de Mallorca & 20.408 & 6 & 10.191 & 9 & $-50,1 \%$ \\
\hline Valencia & 12.169 & 7 & 13.126 & 6 & $7,9 \%$ \\
\hline Tenerife Sur & 9.218 & 8 & 2.797 & 12 & $-69,7 \%$ \\
\hline Zaragoza & 9.160 & 9 & 142.185 & 3 & $1.452,2 \%$ \\
\hline Lanzarote & 7.997 & 10 & 1.825 & 15 & $-77,2 \%$ \\
\hline Málaga-Costa del Sol & 6.811 & 11 & 2.867 & 11 & $-57,9 \%$ \\
\hline Alicante-Elche & 6.037 & 12 & 5.366 & 10 & $-11,1 \%$ \\
\hline Sevilla-San Pablo & 5.053 & 13 & 10.709 & 8 & $111,9 \%$ \\
\hline Santiago de Compostela & 4.939 & 14 & 2.693 & 13 & $-45,5 \%$ \\
\hline Ibiza & 4.510 & 15 & 1.747 & 16 & $-61,3 \%$ \\
\hline Bilbao & 4.153 & 16 & 1.956 & 14 & $-52,9 \%$ \\
\hline Menorca & 3.975 & 17 & 1.474 & 17 & $-62,9 \%$ \\
\hline Fuerteventura & 3.640 & 18 & 947 & 18 & $-74,0 \%$ \\
\hline La Palma & 1.502 & 19 & 617 & 20 & $-58,9 \%$ \\
\hline Vigo-Peinador & 1.030 & 20 & 771 & 19 & $-25,1 \%$ \\
\hline
\end{tabular}

Fuente: Aena, 2018. Elaboración propia.

Zaragoza. Madrid ostenta el mayor nivel de internacionalización, seguido de Barcelona, Zaragoza y Vitoria-Gasteiz.

Respecto al número de aeropuertos en conexión (tabla 5) destaca Madrid, que muestra una estabilidad en esta variable donde decrece el número de conexiones nacionales y aumentan las internacionales; Barcelona pierde conexiones nacionales; Zaragoza casi triplica el número de aeropuertos internacionales conectados; y Vitoria-Gasteiz pierde de forma evidente conexiones nacionales e internacionales por su alta especialización en torno a una serie de destinos específicos. 


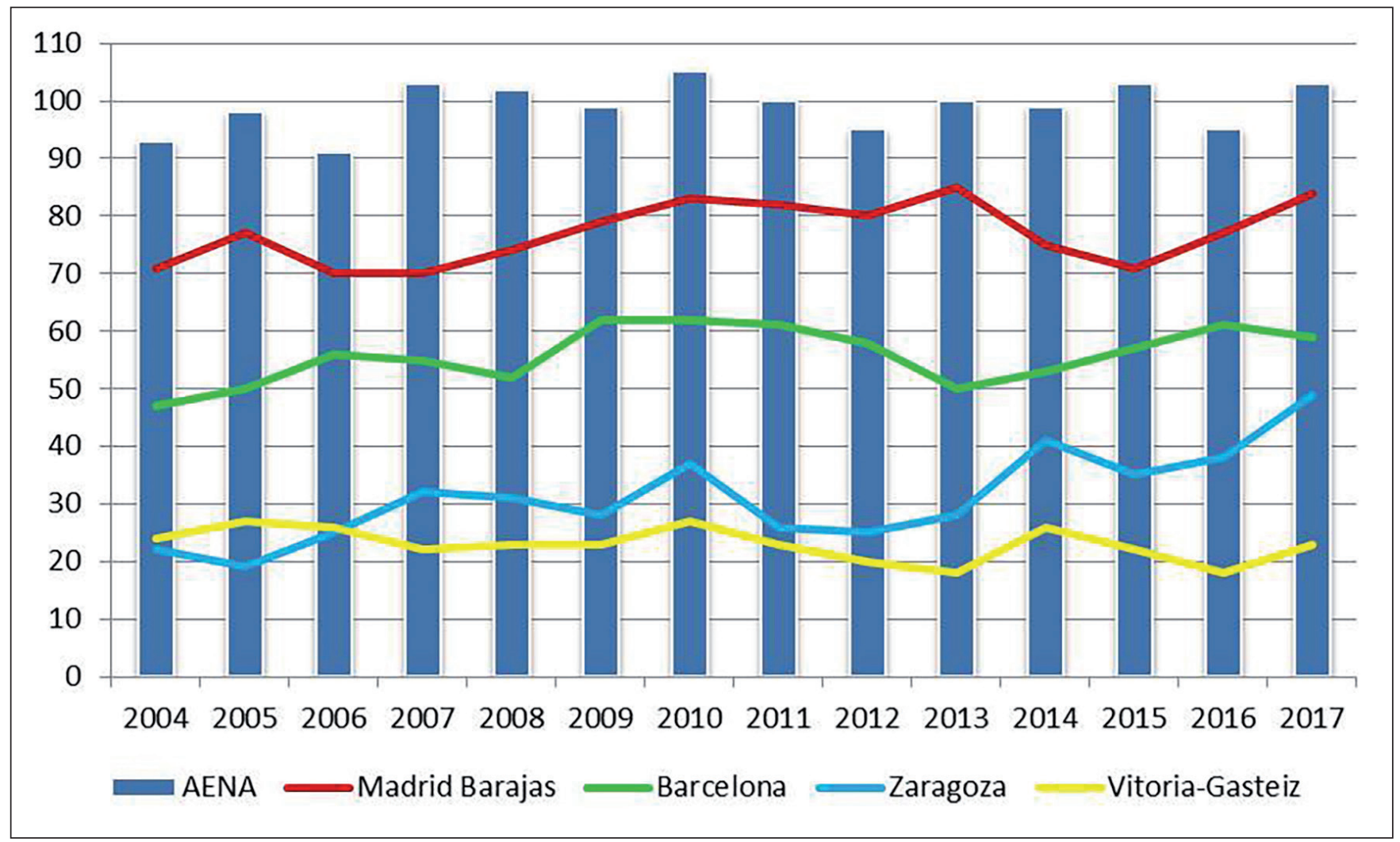

Figura 5. Evolución del número de conexiones internacionales (países) en los cuatro principales aeropuertos de carga aérea por volumen, y en el conjunto de la red Aena, 2004-2017.

Fuente: Aena, 2018. Elaboración propia.

Tabla 5. Evolución del número de conexiones internacionales (aeropuertos) en los cuatro principales aeropuertos de carga aérea por volumen, 2004-2017. Base 2017.

\begin{tabular}{|l|c|c|c|c|c|c|c|}
\hline \multicolumn{1}{|c|}{ Aeropuerto } & \multicolumn{3}{|c|}{2004} & \multicolumn{2}{c|}{$\begin{array}{c}2017 \\
\text { Diferencia número de } \\
\text { conexiones totales (\%) } \\
2004-2017\end{array}$} \\
\cline { 2 - 8 } & Nacional & Internacional & Total & Nacional & Internacional & Total \\
\hline $\begin{array}{l}\text { Adolfo Suárez-Madrid } \\
\text { Barajas }\end{array}$ & 36 & 166 & 202 & 30 & 174 & 204 & $1,0 \%$ \\
\hline Barcelona-El Prat & 33 & 137 & 170 & 27 & 138 & 165 & $-2,9 \%$ \\
\hline Zaragoza & 9 & 38 & 47 & 7 & 100 & 107 & $127,7 \%$ \\
\hline Vitoria-Gasteiz & 12 & 68 & 80 & 7 & 41 & 48 & $-40,0 \%$ \\
\hline $\begin{array}{l}\text { Conjunto de la red } \\
\text { Aena }\end{array}$ & 45 & 337 & 382 & 39 & 335 & 374 & $-2,1 \%$ \\
\hline
\end{tabular}

Fuente: Aena, 2018. Elaboración propia.

\subsection{Evolución de la carga según origen/destino}

Por último, se presentan los resultados atendiendo al origen/destino de la carga de acuerdo a su ámbito geográfico: nacional, países de la Unión Europea, resto de países europeos, resto de países (internacional). En el conjunto del sistema, y como se ha visto en la figura 3, aumenta de forma importante el volumen, así como el porcentaje de la carga internacional en detrimento de la nacional. El análisis de estas tendencias muestra la orientación y especialización tomada por cada uno de los aeropuertos que priman la red (figuras 6, 7, 8 y 9): 


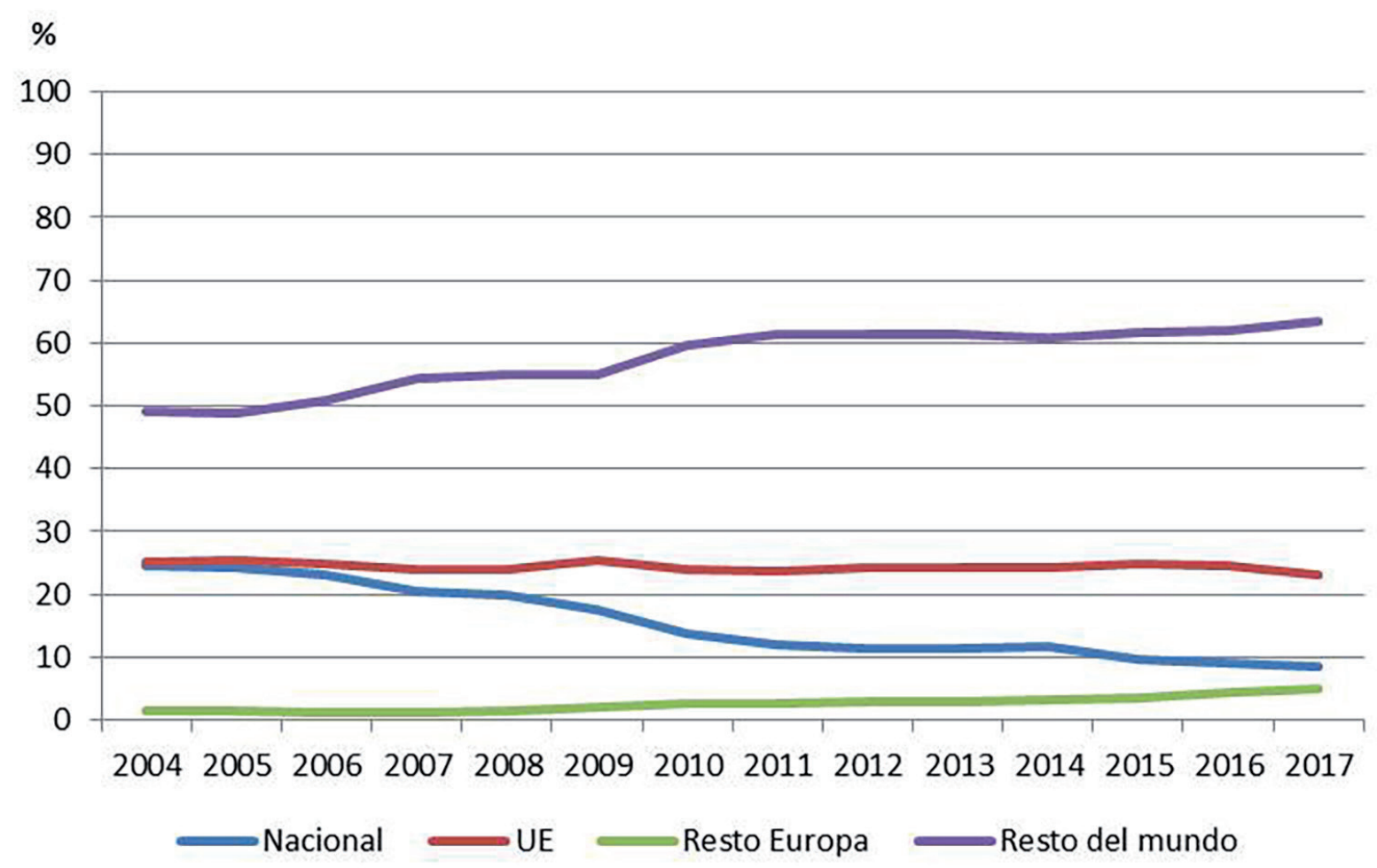

Figura 6. Evolución del tráfico por orígenes/destinos de Adolfo Suárez-Madrid Barajas, 2004-2017. Fuente: Aena, 2018. Elaboración propia.

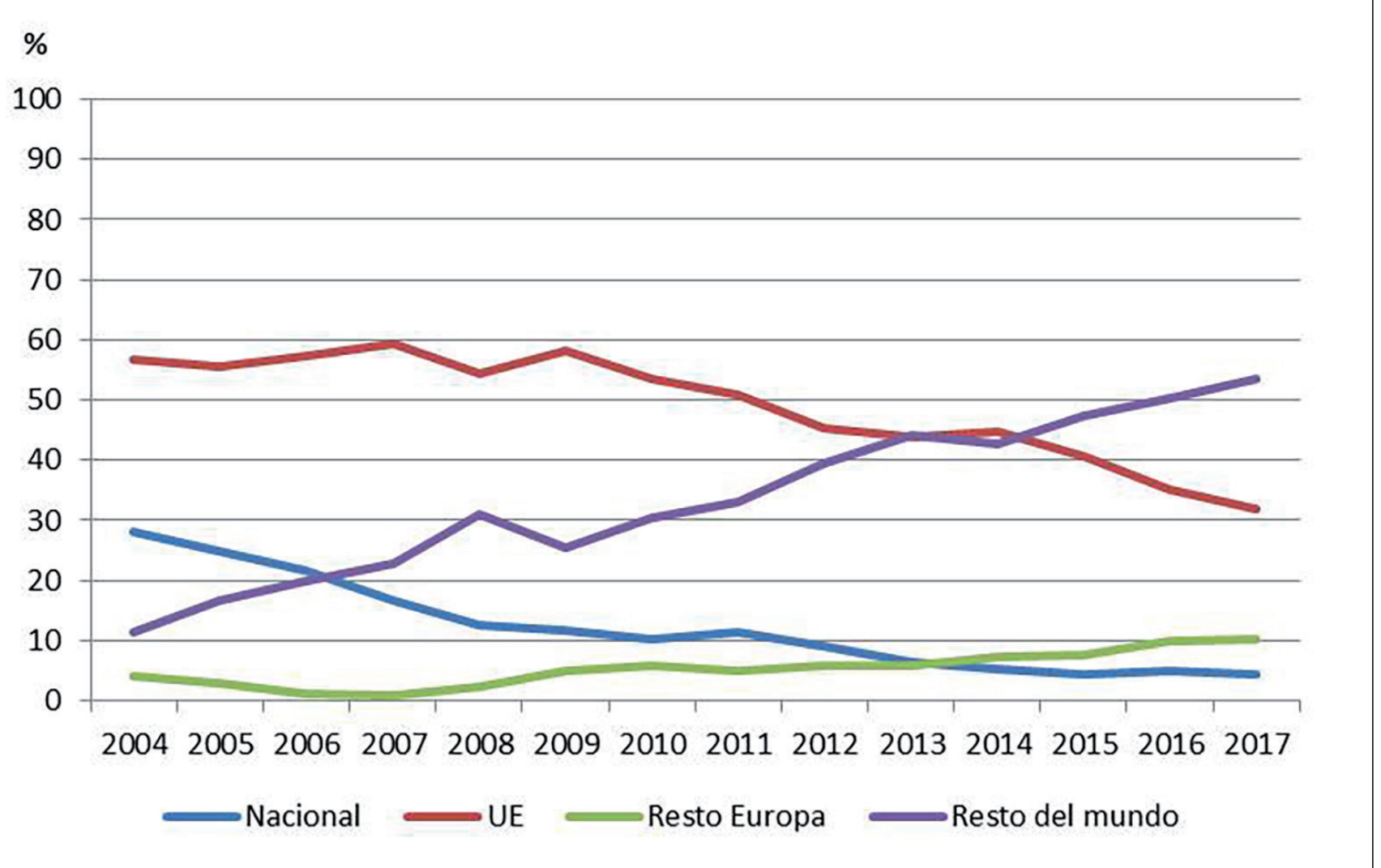

Figura 7. Evolución del tráfico por orígenes/destinos de Barcelona-El Prat, 2004-2017. Fuente: Aena, 2018. Elaboración propia. 


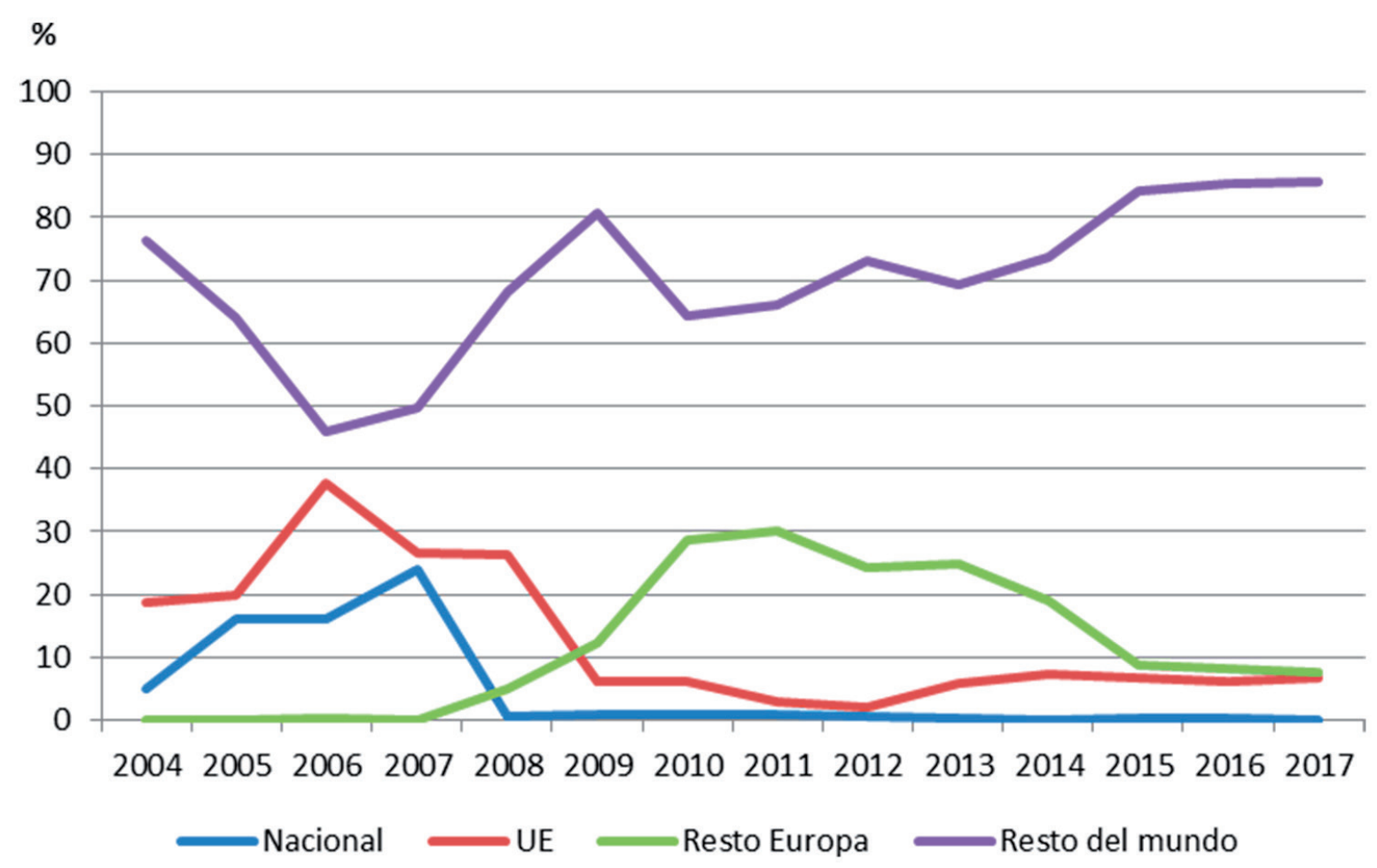

Figura 8. Evolución del tráfico por orígenes/destinos de Zaragoza, 2004-2017. Fuente: Aena, 2018. Elaboración propia.

$\%$

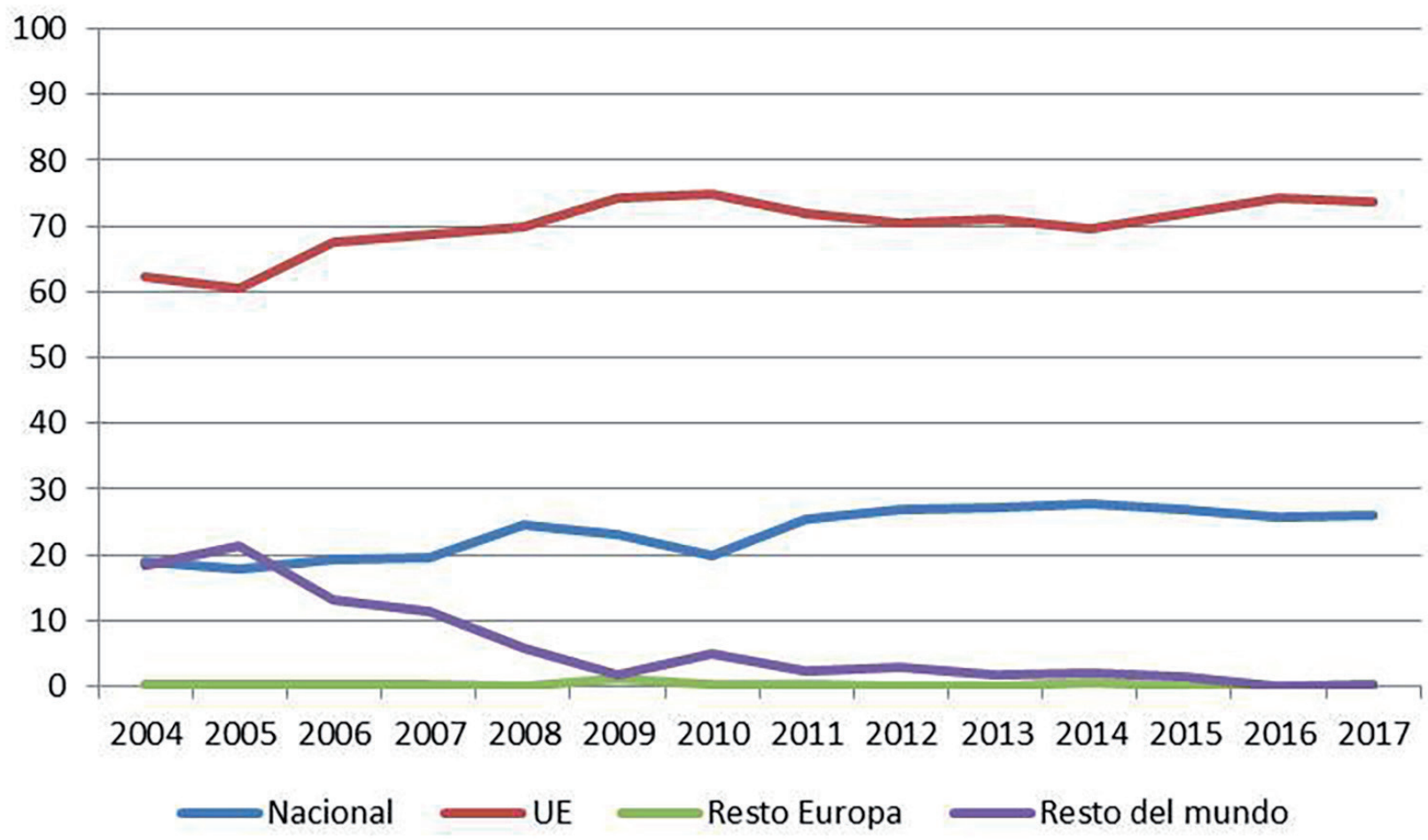

Figura 9. Evolución del tráfico por orígenes/destinos de Vitoria-Gasteiz, 2004-2017. Fuente: Aena, 2018. Elaboración propia. 
1. La carga entre aeropuertos españoles decrece de forma significativa, siendo representativos Madrid, Barcelona y Vitoria-Gasteiz. En los dos primeros la pérdida es relevante, mientras que Vitoria-Gasteiz aumenta levemente su porcentaje de carga destino a otros aeropuertos de la red Aena. Zaragoza pierde prácticamente todas las conexiones nacionales.

2. El intercambio con los países de la Unión Europea se mantiene estable en Madrid y Vitoria-Gasteiz, mientras que pierde peso en Barcelona y Zaragoza.

3. En los desplazamientos con otros aeropuertos europeos que no pertenecen a países de la Unión Europea Madrid y Barcelona aumentan levemente mientras que en Vitoria-Gasteiz son muy poco significativos, y Zaragoza pierde este tipo de conexiones a pesar de que suponían casi una tercera parte de sus conexiones.

4. Por último, los intercambios con aeropuertos de otros continentes crecen en Madrid, aumentan de forma muy significativa en Zaragoza y Barcelona, y desaparecen en Vitoria-Gasteiz.

\section{DISCUSIÓN}

De acuerdo a los resultados obtenidos, y aun considerando su carácter descriptivo, es posible deducir diferentes patrones en los aeropuertos españoles de especial interés para la planificación de sus infraestructuras y de los impactos espaciales y económicos en los próximos años. Se deduce así que los aeropuertos españoles están siguiendo un proceso de concentración en la gestión de la carga aérea paralelo al esquema global, como sugieren otras investigaciones (Sales, M., 2017; Wong, W. H. et al., 2019) donde determinadas ciudades o regiones jerarquizan los flujos globales (Smith, D. A. y Timberlake, M. F., 2001) y se especializan en una economía de logística compleja que responde a los nuevos modelos de la economía mundial.

Además, esta tendencia se ha acentuado tras la Gran Recesión, momento a partir del cual los procesos económicos globales se han reconfigurado afectando especialmente al sector del transporte (Pueyo, Á. y Hernández, M. L., 2013). Cabe destacar además que, a pesar del incremento de la carga total gestionada, las mercancías transportadas entre aeropuertos españoles mantienen una tendencia negativa mientras que aumentan de forma importante los volúmenes hacia y desde el exterior, en especial con países fuera de la Unión Europea, lo que constata el incremento de los flujos de comercio internacional más allá del espacio económico europeo. Para ello, Madrid y Barcelona se presentan como principales nodos entre el sistema global y el internacional al aprovechar su infraestructura y las conexiones de largo radio de pasajeros.

Sin embargo, y a partir de la análisis realizado, cabe reflexionar sobre el papel que están adquiriendo otros nodos intermedios, a los cuales se les puede dar tráfico adicional si son favorecidos por los transportistas como centros de conexión o puntos de retransmisión en el sistema (Fleming, D. K. y Hayuth, Y., 1994). Así, si bien la mayoría de los estudios existentes en este campo incluyen solo las características geoeconómicas de los aeropuertos y sus zonas de influencia como variables explicativas, algunos estudios desarrollan modelos que incorporan más factores que podrían influir en los flujos internacionales de carga aérea operados en los aeropuertos (Hwang, C. C. y Shiao, G. C., 2011; Gong, Q. et al., 2018), evidenciando el papel de los operadores y aerolíneas en sus sistemas de optimización de costes (Bowen Jr., J. T., 2012; Balliauw, M. et al., 2018), en la ubicación de empresas intermediadoras (empresas logísticas, espacios para actividades de transportes, operadores y empresas de provisión de servicios mediante redes digitales, etc.), y en la accesibilidad e intermodalidad con otros medios de transporte más competitivos para la distribución final. Además, esta lógica refuerza el papel de ciertos espacios que ya cuentan con modelos maduros, con fuertes inversiones, con posibilidades de capitalización y jurídicamente seguros para el comercio internacional, lo que restringe y potencia algunos de los espacios ya conocidos e impide su desarrollo en otras zonas de Asia o África.

Asimismo, en la escena internacional se está valorando el papel de los grandes aeropuertos de pasajeros, en muchas ocasiones saturados. En este sentido, son evidentes los casos de éxito de Vitoria-Gasteiz y de 
Zaragoza en España (frente a las instalaciones más concurridas de Madrid y Barcelona), replicando modelos internacionales (a distinta escala e intensidad) como Sharjah y Al-Maktoum en Emiratos Árabes Unidos; Damman en Arabia Saudí; Navoi en Uzbekistán; Zengzhou en China; o Memphis, Louisville y Anchorage en Estados Unidos, entre otros.

La creciente demanda global y las necesidades de especialización e integración de la actividad logística ha llevado, por ejemplo, a posicionar el aeropuerto de Zaragoza como nodo prioritario para el intercambio de mercancías en España, incorporado ahora dentro la cadena global de suministro gracias al desarrollo de una estrategia que combina factores de accesibilidad, logística, calidad, costes ajustados, telecomunicaciones y especialización en la gestión de mercancías textiles (Escalona, A. I., y Ramos, D., 2014). Sobre estas características, cabe añadir su posición intermedia entre Madrid y Barcelona, y en el corredor Cantábrico-Mediterráneo, lo que le otorga un gran potencial para determinados sectores que han de redistribuirse posteriormente. De igual manera, Vitoria aprovecha unas características semejantes, aunque su desarrollo ha sido más débil en los últimos años ya que su especialización en los intercambios nacionales y con otros países europeos le ha restado el potencial de crecimiento que los intercambios internacionales ofrecen, como sucede con el caso de Zaragoza.

De este modo, se constata un desarrollo interesante en los últimos años para determinados sectores y terminales que aprovechan la mejora y expansión de las infraestructuras aeroportuarias (Serrano, J. M., y García, R., 2015), posible gracias a la fuerte inversión en los años previos a la crisis (Pueyo, Á. et al., 2017), así como a la paulatina conversión de la península Ibérica en un hub estratégico para las relaciones entre Europa y América Latina que aprovecha los crecientes lazos con África y Asia.

Por su parte, el aumento del volumen total transportado desde o hacia España contrasta con un incremente mínimo del número de países y un descenso de los aeropuertos con intercambios aéreos en vuelos directos de mercancías, lo cual mostraría la configuración de una red internacional de hubs especializados en carga aérea siguiendo el patrón de los flujos de pasajeros (Bryan, D. L. y O'Kelly, M. E., 1999). Asimismo, a nivel interno el número de instalaciones que gestionaban carga en el año 2000 era mayor al actual a pesar de aumentar el número de aeropuertos integrados en la red Aena. Ambas situaciones sugieren una respuesta del modelo socioeconómico a los procesos globales eficaz para demandas cada vez más diversificadas y ubicuas, que exigen un aumento de la movilidad auspiciado en gran medida por el auge del comercio electrónico, una logística de último kilómetro muy eficiente, y las nuevas pautas de consumo rápidas y flexibles. Por ello, la especialización y el crecimiento de estas terminales de carga sólo es posible si existe una mejora de accesibilidad con el resto de modos de transporte para dar una salida o suministro rápido a las mercancías operadas en los aeropuertos. En ello, el desarrollo de la actividad logística como pieza fundamental para el intercambio global de flujos (Verhetsel, A. et al., 2015) está incidiendo en estos cambios, lo que lleva a la reflexión sobre cómo la configuración de las redes aéreas globales está imponiendo un nuevo modelo de accesibilidad y reorganización territorial que recompone el esquema tradicional de dependencia derivada de localización y distancia (Antón, F. J., 2013).

Todo ello está conllevando importantes impactos territoriales como el desarrollo de espacios logísticos, industriales y terciarios que, sin embargo, todavía no han alcanzado en España el desarrollo de otros espacios globales (Hesse, M., 2014; Al-Mehairi, J. M., 2016). Así, el factor de localización sigue siendo determinante para alcanzar grandes volúmenes de operaciones (Hesse, M., 2014; Al-Mehairi, J. M., 2016), por lo que es necesario dotarse de infraestructuras y servicios, profundizando asimismo en la investigación de las interrelaciones socioeconómicas e impactos territoriales que genera el transporte aéreo de mercancías (Graham, A., 2005; Escalona, A. I., y Ramos, D., 2010; Mayer, R., 2016). Específicamente, en el caso de España el desarrollo de la actividad logística requiere una planificación integrada entre las infraestructuras de transporte y el desarrollo de los usos del suelo que solucione eficientemente las nuevas demandas y necesidades (López, C., 2017). En especial, respecto a los retos que supone el auge del comercio electrónico, que está conllevando una reordenación de las cadenas y modos de gestión de distribución de las mercancías que presenta sus propios efectos locales, como la multiplicación de áreas destinadas a la gestión logística (Hesse, M. y Rodrigue, J. P., 2004). 


\section{CONCLUSIONES}

Este trabajo ha presentado un análisis sobre la evolución reciente de la gestión de carga aérea en los aeropuertos españoles. Los resultados han permitido vislumbrar cómo el volumen de carga aérea en España ha aumentado de forma importante tras la crisis económica en 2008 y, al mismo tiempo, cómo la actividad se ha concentrado en un número menor de aeropuertos. Ello muestra la especialización de determinadas instalaciones que se apoya en la reconfiguración en el modelo logístico y de distribución de las mercancías transportadas por vía aérea, replicando el modelo existente en el conjunto del sistema aéreo global y europeo.

De este modo, la organización internacional actual de la carga aérea ha influido sobre el sistema aeroportuario español, reconfigurando la jerarquía aeroportuaria. En la actualidad, la funcionalidad del sistema de carga aérea se encuentra extremadamente polarizada en cuatro aeropuertos que concentraron en 2017 más del 90\% del volumen total. Estos son Madrid, Barcelona, Zaragoza y Vitoria-Gasteiz. Específicamente, Adolfo Suárez-Madrid-Barajas se ha consolidado como nodo global de carga aérea con origen/destino nacional e internacional, mientras que Barcelona-El Prat mantiene una segunda posición con un papel menos relevante con una orientación internacional. Ambos tienen pendiente la ampliación y mejora de capacidad mediante nuevos planes directores que incluyen la creación de espacio logístico y de servicios, por lo que cabe estar atentos a si estas inversiones conducirán más si cabe a una concentración mayor en torno a ambos aeropuertos. Además, debe destacarse la irrupción del aeropuerto de Zaragoza hasta la tercera posición (con unos valores muy próximos a Barcelona en 2017), gracias al desarrollo de un modelo de gestión logística, especialización sectorial en distribución de carga aérea textil, y aprovechando su estratégica situación en el centro del cuadrante nororiental de la península Ibérica donde se concentra la mayor parte del PIB y del tejido industrial y de servicios; apoyado en una excelente accesibilidad con otros modos de transporte. Vitoria-Gasteiz mantiene un peso todavía relevante sobre el conjunto, aunque su orientación hacia conexiones de medio alcance le está restando posibilidades para alcanzar los grandes volúmenes propios de la carga aérea intercontinental.

Consecuentemente, en los próximos años la previsión de crecimiento de la demanda de transporte aéreo de mercancías va a requerir la ampliación de terminales y la construcción de nuevas instalaciones especializadas, la presencia de plataformas multimodales, modelos automatizados, sistemas de distribución mediante inteligencia artificial y el desarrollo de sistemas de gestión en tiempo real que permitan ubicuidad, adaptabilidad y flexibilidad total. Ello muestra un desafío para gobiernos y empresas en un momento en el que la hibridación físico-digital y la automatización de todos los procesos de las cadenas productivas y de distribución supondrán nuevos escenarios y retos para los territorios tanto en las escalas globales como locales en un escenario flexidimensional en el que la mano de obra clásica será suplantada por otras formas de cooperación hombre-máquina-sistemas inteligentes. Sin embargo, estos procesos mejorarán y optimizarán el modelo de organización de las grandes empresas de transporte, complementando un modelo de hubs globales reducidos sobre los que pivotan el grueso de la distribución de mercancías en el contexto de un sistema de distribución sumamente flexible.

\section{REFERENCIAS}

Aeropuertos Españoles y Navegación Aérea (2018). Recuperado de http://www.aena.es/csee/Satellite?pagename=Estadisticas/Home Último acceso: 10 de octubre de 2018.

Akhavan, M. (2017). Evolution of hub port-cities into global logistics centres. International Journal of Transport Economics, 44 (1), 25-47. doi: 10.19272/201706701002

Al-Mehairi, J. M. (2016). Dubai's geographic location and its advantages for the air transportation industry. Arab World Geographer, 19 (3-4), 352-367. doi: https://doi.org/10.5555/i1480-6800.19.3.352

Antón Burgos, F. J., y Córdoba y Ordóñez, J. A. (1994). La liberalización del transporte aéreo en España. Boletín de la Asociación de Geógrafos Españoles, 19, 113-132. 
Antón Burgos, F. J. (2013). Redes de transporte, articulación territorial y desarrollo regional. Revista de Estudios Andaluces 30, 27-47. doi: http://dx.doi.org/10.12795/rea.2013.i30.02

Balliauw, M., Meersman, H., Onghena, E. \& Van de Voorde, E. (2018). "US all-cargo carriers" cost structure and efficiency: A stochastic frontier analysis. Transportation Research Part A: Policy and Practice, 112, 29-45. doi: https://doi. org/10.1016/j.tra.2018.01.005

Behrens, K. (2007). On the location and lock-in of cities: Geography vs transportation technology. Regional Science and Urban Economics, 37, 22-45. doi: https://doi.org/10.1016/j.regsciurbeco.2006.04.003

Boeing (2017). World Air Cargo Forecast 2016-2017. Recuperado de http://www.boeing.com/resources/boeingdotcom/ commercial/about-our-market/cargo-market-detail-wacf/download-report/assets/pdfs/wacf.pdf Último acceso: 05 de octubre de 2018.

Bowen Jr., J. T. (2012). A spatial analysis of FedEx and UPS: Hubs, spokes, and network structure. Journal of Transport Geography, 24, 419-431. doi: https://doi.org/10.1016/j.jtrangeo.2012.04.017

Bryan, D. L. \& O’Kelly, M. E. (1999). Hub-and-spoke networks in air transportation: An analytical review. Journal of Regional Science, 39 (2), 275-295. doi: https://doi.org/10.1111/1467-9787.00134

Coe, N. M. \& Yeung, H. W. -c. (2015). Global production networks: Theorizing economic development in an interconnected world. Oxford: Oxford University Press. doi: https://doi.org/10.1093/acprof:oso/9780198703907.001.0001

Córdoba Ordóñez, J. A. y Gago García, C. (2012). Globalización, movilidad y análisis de conectividad aérea: Una herramienta para la práctica interdisciplinar. Revista de Antropología Social, 21 (1), 117-146. doi: http://dx.doi.org/10.5209/ rev_RASO.2012.v21.40052

Dang, Y. R. \& Peng, L. N. (2012). Hierarchy of air freight transportation network based on centrality measure of complex networks. Jiaotong Yunshu Xitong Gongcheng Yu Xinxi/ Journal of Transportation Systems Engineering and Information Technology, 12 (3), 109-114. doi: https://doi.org/10.1016/S1570-6672(11)60207-9

Derudder, B., Witlox, F., Faulconbridge, J. \& Beaverstock, J. (2008). Airline networks and urban systems (Editorial). GeoJournal 71 (1), 1-3. doi: https://doi.org/10.1007/s10708-008-9151-y

Díez Pisonero, R., Gago García, C., y Córdoba Ordóñez, J. A. (2016). Los aeropuertos de la globalización. Espectacularización y teatralización de la infraestructura como herramienta de citymarketing. Boletín de la Asociación de Geógrafos Españoles 72, 221-247. doi: http://dx.doi.org/10.21138/bage.2338

Dilian, C. D. \& White C. L. (eds.) (2010). Trade and Exchange: Archaeological Studies from History and Prehistory. Springer.

Escalona Orcao, A. I. y Ramos Pérez, D. (2010). Geografía productiva y flujos internacionales de transporte: el crecimiento de la carga aérea en el aeropuerto de Zaragoza. Anales de Geografía de la Universidad Complutense, 30 (2), $59-80$. Recuperado de http://revistas.ucm.es/index.php/AGUC/article/view/AGUC1010220059A/30703

Escalona Orcao, A. I. y Ramos Pérez, D. (2014). Global production chains in the fast fashion sector, transports and logistics: the case of the Spanish retailer Inditex. Investigaciones Geográficas, Boletín del Instituto de Geografía, 85, 113127. doi: https://doi.org/10.14350/rig.40002

Eurostat (2016). Recuperado de http://ec.europa.eu/eurostat/statistics-explained/index.php?title=File:Top-20_airports_ in_the_EU-28_in_terms_of_total_freight_and_mail_loaded_unloaded_in_2016.png Último acceso: 20 de octubre de 2018.

Fleming, D. K. \& Hayuth, Y. (1994). Spatial characteristics of transportation hubs: centrality and intermediacy. Journal of Transport Geography, 2 (1), 3-18. doi: https://doi.org/10.1016/0966-6923(94)90030-2

Fung, M. K. Y., Zhang, A., Leung, L. C. K. \& Law, J. S. (2005). The air cargo industry in China: Implications of globalization and WTO accession. Transportation Journal, 44 (4), 44-62.

Gago García, C. (2002). Estructura geo-económica mundial, globalización y flujos comerciales. Estudios geográficos, 63 (246), 143-153. Recuperado de http://estudiosgeograficos.revistas.csic.es/index.php/estudiosgeograficos/article/ view/264/263

Gago García, C. y Córdoba Ordóñez, J.A. (2013). Sistemas urbanos en América Latina: Roles y advenimientos de nuevos centros desde la perspectiva del transporte aéreo. Anales de Geografía de la Universidad Complutense, 33 (2), 9-39. doi: http://dx.doi.org/10.5209/rev_AGUC.2013.v33.n2.43000

Graham, A. (2005). Airport benchmarking: a review of the current situation. Benchmarking: An International Journal, 12 (2), 99-111. doi: https://doi.org/10.1108/14635770510593059 
Gong, Q., Wang, K., Fan, X., Fu, X. \& Xiao, Y. B. (2018). International trade drivers and freight network analysis - The case of the Chinese air cargo sector. Journal of Transport Geography, 71, 253-262. doi: https://doi.org/10.1016/j.jtrangeo.2017.02.009

Guimerà, R. \& Amaral, L. A. N. (2004). Modeling the world-wide airport network. European Physical Journal B, vol. 38 (2), 381-385. doi: 10.1140/epjb/e2004-00131-0

Hesse, M. \& Rodrigue, J. P., (2004). The transport geography of logistics and freight distribution. Journal of Transport Geography 12,171-184. doi: https://doi.org/10.1016/j.jtrangeo.2003.12.004

Hesse, M. (2014). International hubs as a factor of local development: evidence from Luxembourg City, Luxembourg, and Leipzig, Germany. Urban Research and Practice, 7 (3), 337-353. doi: https://doi.org/10.1080/17535069.2014.966508

Hui, G. W. L., Hui, Y. V. \& Zhang, A. (2004). Analyzing China's air cargo flows and data. Journal of Air Transport Management, 10 (2), 125-135. doi: https://doi.org/10.1016/j.jairtraman.2003.08.003

Hwang, C. C. \& Shiao, G. C. (2011). Analyzing air cargo flows of international routes: an empirical study of Taiwan Taoyuan International Airport. Journal of Transport Geography, 19 (4), 738-744. doi: https://doi.org/10.1016/j.jtrangeo.2010.09.001

IATA (2017). World Air Transport Statistics. [En línea]. International Air Transport Association. Recuperado de http://www. iata.org/pressroom/media-kit/Documents/WATS-2017-mediakit-summary.pd Último acceso: 25 de enero de 2013.

Jiménez, J. L. \& Betancor, O. (2012). When trains go faster than planes: The strategic reaction of airlines in Spain. Transport Policy 23, 34-41. doi: https://doi.org/10.1016/j.tranpol.2012.06.003

Lim, S. F. W. T., Jin, X. \& Srai, J. S. (2018). Consumer-driven e-commerce: A literature review, design framework, and research agenda on last-mile logistics models. International Journal of Physical Distribution and Logistics Management, 48 (3), 308-332. doi: https://doi.org/10.1108/IJPDLM-02-2017-0081

López Escolano, C., Pueyo Campos, A., Valdivielso Pardos, S., y Hernández Navarro, M. L. (2015). Transformaciones espaciales y de actividad frente a las dinámicas globales en el entorno metropolitano de Zaragoza. En A. Espinosa Seguí, F. J. Antón Burgos (Eds), El papel de los servicios en la construcción del territorio: redes y actores (vol. 1, pp. 285-302). Alicante: Asociación de Geógrafos Españoles.

López Escolano, C. (2017). Valoración de las transformaciones territoriales de la España peninsular mediante el estudio de la red viaria, indicadores de accesibilidad y de potencial de población. Tesis doctoral, Universidad de Zaragoza. Consejo Económico y Social de Aragón. Recuperado de http://www.aragon.es/estaticos/GobiernoAragon/OrganosConsultivos/ConsejoEconomicoSocialAragon/Areas/Publicaciones/TESIS/2018/TESIS_RED_VIARIA.pdf Último acceso: 30 de octubre de 2018.

Lotti, R. \& Caetano, M. (2018). The airport choice of exporters for fruit from Brazil. Journal of Air Transport Management 70 , 104-112. doi: https://doi.org/10.1016/j.jairtraman.2018.05.003

Martí-Henneberg, J., Tapiador, F. J., y Pueyo, A. (2007). La eclosión de los aeropuertos regionales españoles. Universidad de Lleida, Universidad de Castilla-La Mancha y Universidad de Zaragoza.

Martín, J. C., Román, C., García-Palomares, J. C. \& Gutiérrez, J. (2014). Spatial analysis of the competitiveness of the high-speed train and air transport: The role of access to terminals in the Madrid-Barcelona corridor. Transportation Research Part A, 69, 392-408. doi: https://doi.org/10.1016/j.tra.2014.09.010

Matsumoto, H. (2004). International urban systems and air passenger and cargo flows: Some calculations. Journal of Air Transport Management, 10 (4), 241-249. doi: https://doi.org/10.1016/j.jairtraman.2004.02.003

Mayer, R. (2016). Airport classification based on cargo characteristics. Journal of Transport Geography, 54, 53-65. doi: https://doi.org/10.1016/j.jtrangeo.2016.05.011

Ministerio de Fomento (2018). Recuperado de https://www.fomento.gob.es/MFOM/LANG_CASTELLANO/DIRECCIONES_GENERALES/AVIACION_CIVIL/POLITICAS_AEROPORTUARIAS/ITA/PLANES_DIRECTORES/ Último acceso: 02 de noviembre de 2018.

Morrell, P. S. (2011). Moving Boxes by Air: The Economics of International Air Cargo. Abingdon: Routledge.

O'Kelly, M. E. (1998). A geographer's analysis of hub-and-spoke networks. Journal of Transport Geography, 6 (3), $171-186$. doi: https://doi.org/10.1016/S0966-6923(98)00010-6

Pueyo Campos, A. y Hernández Navarro, M. L. (2013). L’Espagne face à la Grande Récession depuis 2008. M@ppemonde, 111 (3). Recuperado de https://mappemonde-archive.mgm.fr/num39/articles/art13301_fr.pdf 
Pueyo Campos, A., López Escolano, C., y Hernández Navarro, M. L. (2017). La tensión entre las dinámicas productivas y residenciales. El papel de las infraestructuras. En J. Farinós Dasí, J. Olcina Cantos (eds. y coords.) Geografía Regional de España: Espacio y comunidades (pp. 371-425). Valencia: Tirant lo Blanch.

Pueyo Campos, A., López Escolano, C., y Hernández Navarro, M. L. (2018). Nuevos espacios y realidades a partir del análisis espacial: un territorio distinto de ideas preconcebidas. En J. Farinós Dasí, J. (coord.) y J. Farinós y E. Peiró (eds.) Territorio y Estados. Elementos para la coordinación de las políticas de ordenación del territorio en el siglo XXI (pp. 785-828). Valencia: Tirant lo Blanch.

Ramos Pérez, D., Gámir Orueta, A., y Escalona Orcao, A. I. (2013). Ayudas públicas y oferta de servicios aéreos en los aeropuertos españoles. Boletín de la Asociación de Geógrafos Españoles, 61, 25-46. doi: http://dx.doi.org/10.21138/ bage. 1534

Rey, M. B. (2003). Structural changes in the Spanish scheduled flights market as a result of air transport deregulation in Europe. Journal of Air Transport Management, 9 (3), 195-200. doi: https://doi.org/10.1016/S0969-6997(02)00097-2

Rodrigue, J. P., Comtois, C. \& Slack, B. (2017). The Geography of Transport Systems. Abingdon: Routledge. doi: https://doi. org/10.4324/9781315618159

Sales, M. (2017). Air Cargo Management: Air Freight and the Global Supply Chain. Abingdon: Routledge. doi: https://doi. org/10.4324/9781315620169

Savy, M. (2004). Croissance économique et transports des marchandises: le découplage en débat. Les Sens du movement. París: Belin.

Serrano Martínez, J. M. y García Marín, R. (2015). Aeropuertos locales y de reducido tráfico en España: dificultades y necesaria reordenación de la red aeroportuaria territorial. Boletín de la Asociación de Geógrafos Españoles, 67, 497-505. doi: http://dx.doi.org/10.21138/bage.1832

Smith, D. A. y Timberlake, M. F. (2001). World city networks and hierarchies, 1977-1997: an empirical analysis of global air travel links. American Behavioral Scientist, 44 (10), 1656-1678. doi: https://doi.org/10.1177/00027640121958104

Suau-Sánchez, P. \& Burghouwt, G. (2011). The geography of the Spanish airport system: Spatial concentration and deconcentration patterns in seat capacity distribution, 2001-2008. Journal of Transport Geography, 19 (2), $244-254$. https://doi.org/10.1016/j.jtrangeo.2010.03.019

Suwanwong, T., Sopadang, A., Hanaoka, S. \& Rodbundith, T. (2018). Evaluation of air cargo connectivity and policy in Thailand. Transport Policy, 72, 24-33. doi: https://doi.org/10.1016/j.tranpol.2018.09.005

Tapiador, F.J., Mateos, A. \& Martí-Henneberg, J. (2008). The geographical efficiency of Spain's regional airports: A quantitative analyses. Journal of Air Transport Management, 14, 205-212. doi: https://doi.org/10.1016/j.jairtraman.2008.04.007

Tovar, B., Hernández, R. \& Rodríguez-Déniz, H. (2015). Container port competitiveness and connectivity: The Canary Islands main ports case. Transport Policy, 38, 40-51. doi: https://doi.org/10.1016/j.tranpol.2014.11.001

Verhetsel, A., Kessels, R., Goos, P., Zijlstra, T., Blomme, N. \& Cant, J. (2015). Location of logistics companies: a stated preference study to disentangle the impact of accessibility. Journal of Transport Geography, 42, 110-121. doi: https:// doi.org/10.1016/j.jtrangeo.2014.12.002

Walcott, S. M. y Fan, Z. (2017). Comparison of major air freight network hubs in the U.S. and China. Journal of Air Transport Management, 61, 64-72. https://doi.org/10.1016/j.jairtraman.2016.06.006

Wong, W. H., Cheung, T., Zhang, A. \& Wang, Y. (2019). Is spatial dispersal the dominant trend in air transport development? A global analysis for 2006-2015. Journal of Air Transport Management, 74, 1-12. doi: https://doi.org/10.1016/j.jairtraman.2018.09.011

Yamaguchi, K. (2008). International trade and air cargo: Analysis of US export and air transport policy. Transportation Research Part E: Logistics and Transportation Review, 44 (4), 653-663. doi: https://doi.org/10.1016/j.tre.2007.05.006

Zhang, A. (2003). Analysis of an international air-cargo hub: The case of Hong Kong. Journal of Air Transport Management, 9 (2), 123-138. doi: https://doi.org/10.1016/S0969-6997(02)00066-2 